\title{
Família e Habitat \\ Dinâmicas Sócio-Demográficas, Valores e Formas de Apropriação do Alojamento
}

Ana Cristina Ferreira*

\begin{abstract}
$\mathrm{R}$ por base a pesquisa Quálidade de Vida nas periferi dissertação de doutoramento que teve Metropolitana de Lisboa, enquadrada num projecto financiado pela Fundação para a Ciência e Tecnologia e realizada entre Janeiro de 1997 e Junho de 2000. Este trabalho tinha como objectivo principal relacionar as dinâmicas sócio-demográficas e a apropriação do alojamento. Tendo como pano de fundo as alterações demográficas verificadas em Portugal nas últimas décadas, analisou-se o grau de satisfação e aspirações dos inquiridos face ao alojamento e ao habitat, diferenciando-os de acordo com a faixa etária em que se encontram, a área de residência (Lisboa, Área Metropolitana a Norte do Tejo e Área Metropolitana a Sul do Tejo), a propriedade/ausência de propriedade do alojamento e o tipo de família em que se encontram inseridos. Por outro lado, e numa tentativa de responder a algumas teses que apontam para a "morte da família", dá-se conta da importância que esta instituição parece ter, pelo menos para os inquiridos. Para tal, tentou aferir-se onde e a quem os diversos tipos de família vão buscar diferentes auxílios, com quem contam e para quê e os valores que tentam incutir às novas gerações.
\end{abstract}

Palavras-chave: família; alojamento; habitat; áre metropolitana de Lisboa.

Pretende-se com este artigo dar conta de alguns resultados da pesquisa que esteve na base da dissertação de doutoramento defendida em Maio de 2003 no ISCTE'.

Este trabalho tinha como objectivos relacionar as dinâmicas sócio-demográficas e a apropriação do alojamento. Particularmente, visava perceber alterações verificadas na família e a importância dos valores familiares, estudar a interacção família/habitat nas diferentes fases do ciclo de vida, entender expectativas de mobilidade residencial, analisar as formas de gestão das sociabilidades e das entreajudas e, finalmente, analisar a percepção da qualidade de vida face a factores como as condições de ambiente e instalação de equipamentos ${ }^{2}$.

Escolher uma casa não representa somente escolher uma habitação para morar, o número de quartos e a sua dimensão, a sua disposição face ao sol e à luminosidade. Significa também escolher um bairro, escolher uma vizinhança, atender à proximidade face ao trabalho, a equipamentos e serviços e à relação com a cidade - o que implica passar do conceito de alojamento ao conceito de habitat.

Para Bertrand e Chevalier (1998) "Dans les aléas de choix d'un voisinage ou d'un quartier, il est clair que les possibilités de mobilité

\footnotetext{
Doutorada em em Sociølogia, Prøfessora auxiliar do ISCTE. Cøntacto: cristina.ferreira@iscte.pt

A referida tese teve como orientadora a Professora Doutora Isabel Guerra e como co-orientador o Professor Doutor Rui Menezes.

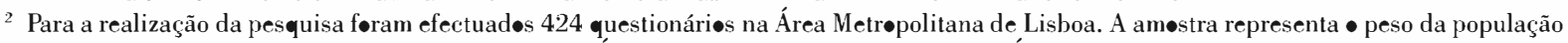
com 15 anos ou mais presente em três sub-áreas: Área Metropolitana a Norte do Tejo, Área Metropolitana a Sul do Tejo e Lisboa. Estas

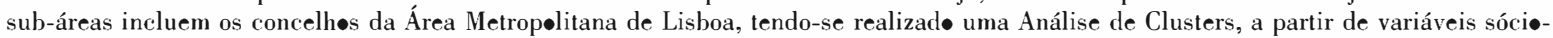
demográficas, análise esta que permitiu chegar a cinco grupos homogéneos: dois a norte do Tejo, dois a Sul e Lisboa. Recolheu-se então a

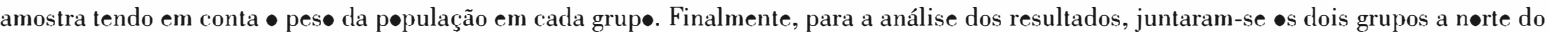
Tejo (AMN) e os dois a sul (AMS).
} 
résidentielles des individus, des ménages et des groupes, interviennent pour que la meilleure adéquation aux besoins de la vie sociale se réalise. De plus, les possibilités de mobilité générale des individus et des groupes permettent à certains de recentrer leur espace social sur la résidence en consentat pour les autres activités des déplacements importants."(Bertrand e Chevalier, 1998: 14).

Esta perspectiva não é, obviamente, nova; desde os anos 80, que vários autores, nomeadamente franceses, através de análises longitudinais, levam a cabo estudos com este enfoque, o que conduz Catherine Bonvalet a afirmar que "comprendre la famille c'est aussi analyser à quel endroit elle vit, dans quel logement" (1991: 165).

\section{As mudanças nas famílias e formas de habitar: referencial teórico}

O quadro de referência da pesquisa realizada encontrava-se estruturado em função de três nós problemáticos fundamentais. Em primeiro lugar, as transformações nas dinâmicas familiares; em segundo lugar, os impactos dessas alterações demográficas na criação de novas necessidades face ao habitat; em terceiro lugar, o confronto entre um modo de vida central e um modo de vida suburbano.

\section{Transformações nas dinâmicas familiares}

São várias as transformações sociais ocorridas ao nível da vida familiar das quais as mais destacadas se articulam com profundas alterações demográficas. Ao nível das dinâmicas familiares e modos de organização familiares verifica-se um decréscimo da dimensão média das famílias, decréscimo que tem origem em dois factores: a transição demográfica implicou uma redução da natalidade a par com o aumento da esperança média de vida. Os meios de controlo de natalidade difundiram-se e, nos nossos dias, o investimento afectivo nos filhos, na sua educação, etc., levam os casais a optar por reduzir o número de descendentes. Outros fenómenos, como o aumento do número de pessoas vivendo sós, pelo menos nalgumas fases do seu ciclo de vida, como por exemplo, após um divórcio ou uma viuvez, vêm também aumentar a procura de casas disponíveis. Verifica-se ainda uma grande e brusca quebra da natalidade que as actuais teorias da transição demográfica tentam explicar em função das alterações já referidas.

Por outro lado, assiste-se, com o avanço da ciência, das condições de higiene e de vida, etc., a um grande aumento da esperança de vida. Este decréscimo da natalidade e o aumento da esperança de vida provocam profundas alterações nos comportamentos demográficos, nomeadamente a diminuição da dimensão das famílias, o aumento dos lares de "ninho vazio" e o acréscimo do número de pessoas sós, principalmente mulheres viúvas, pois é o sexo feminino que maior esperança de vida apresenta. Face a este aumento da esperança de vida, as habitações das famílias actuais têm de estar preparadas para acolher, pelo menos temporariamente, os idosos, os quais, em caso de doença, viuvez, etc., são muitas vezes acolhidos em casa dos filhos (frequentemente das filhas) embora, quando a situação de dependência perdura e existem condições económicas para o fazer, sejam frequentemente encaminhados para instituições especializadas.

Está-se, também, perante transformações que são profundamente culturais. A passagem da família instituição ${ }^{3}$ à família companheirismo ${ }^{4}$ e a inerente importância conferida ao amor no interior do casamento e ainda a alteração do papel da mulher, fruto da sua maior inserção no mercado de trabalho que lhe vem possibilitar uma independência económica que antes não possuía. Este facto, a par da concepção de que o "amor só é eterno enquanto dura" e o casamento tem a duração do amor (relação pura, no sentido de Giddens) conduzem a um acréscimo muito acentuado do divórcio e das famílias recompostas.

Estas transformações familiares são, em larga medida, transformações dos "estilos de vida". Ora, o alojamento e o espaço onde se vive é, social e culturalmente, uma parte desse estilo de vida, manifestando-se estas transformações nas formas de viver o alojamento e o habitat.

\footnotetext{
${ }^{3}$ Forma de família das sociedades onde o interesse societal prevalece sobre o interesse individual e, em consequência, a escolha do cônjuge é feita de acordo com o interesse colectivo.

${ }^{4}$ Forma de família da sociedade moderna, onde a escolha do cônjuge é feita de acordo com o interesse individual e onde o amor está na base do casamento.
} 


\section{Impactos das alterações demográficas na criação de novas necessidades face ao habitat}

Uma das características dos novos modos de vida familiares relaciona-se com o ciclo de vida dos filhos nomeadamente dos jovens que deixam a casa dos pais cada vez mais tarde sendo necessário que a habitação, muitas vezes adquirida quando os filhos eram pequenos, tenha condições para propiciar uma autonomia ao jovem adulto vivendo com os ascendentes, de molde a minimizar os conflitos e a garantir a possibilidade de fazer funcionar estas novas formas de interacção familiar que se desenham nas famílias contemporâneas. Já vai sendo frequente, especialmente nas cidades, os jovens casais coabitaram sem possibilidade de arrendar ou comprar uma habitação autónoma dos pais. Nas famílias com recursos, assiste-se ainda ao arrendamento ou compra de apartamentos por parte dos pais que os cedem aos filhos para viverem sozinhos ou em casal, casados ou em união de facto. Por outro lado, começou a ser relativamente comum tal acontecer quando, por exemplo, um filho vai estudar para uma cidade longe da casa de família.

Embora alguns estudos dêem conta da inexistência de uma relação directa entre as alterações familiares - os tipos de família e as fases do ciclo de vida - e as alterações ao nível do alojamento, algumas conclusões de trabalhos realizados mostram que o decréscimo da dimensão da família não implica residências menores, nem em áreas nem em número de assoalhadas (o que o trabalho aqui em discussão vem comprovar). $\mathrm{O}$ aumento da divorcialidade traz, também, consigo a necessidade de uma certa flexibilidade do mercado de alojamento, que muitas vezes não existe. $\mathrm{O}$ casal divorcia-se e, pelo menos um deles, pode ficar sem alojamento, recorrendo por uns tempos à casa dos pais ou ao mercado de arrendamento. Nos grupos socioeconómicos mais favorecidos, vende-se o alojamento da família e cada um dos ex-cônjuges poderá adquirir ou arrendar um novo alojamento. Quando existem filhos estas novas residências carecem de alguns requisitos. Ambos os progenitores pretendem ter condições para alojar os filhos, seja qual for o progenitor que fique com a guarda dos menores. Idealmente, as habitações não deverão ser muito distantes para possibilitar o fácil transporte para a escola e outras actividades por parte de ambos os pais.

Estamos, ainda, face a uma transformação das exigências domésticas com a necessidade de espaços de apropriação individualizada, de privacidade, em que o alojamento serve o projecto reflexivo do $e u$ (Giddens). Por outro lado, existem mais equipamentos domésticos e de lazer trazidos para o interior do alojamento; é frequente, hoje em dia, a necessidade, ou pelo menos a aspiração, da existência de um escritório em casa que alberga o computador para trabalhar, necessidade especialmente sentida, pelo menos em certas camadas sociais, pelo facto da mulher estar também inserida no mercado de trabalho e de, em certos casos, necessitar de realizar trabalho ou actualização de conhecimentos em casa, por vezes com auxílio informático.

Por outro lado, se cada membro da família, à excepção do casal, deseja um quarto só para si, este desejo de privacidade implica também necessidades de espaços comuns (com certa amplitude) para o convívio da família.

Assiste-se, ainda, a uma proliferação de electrodomésticos que vêm simplificar as tarefas domésticas tradicionalmente associadas à mulher (máquinas de lavar roupa e louça, máquinas de secar roupa, cada vez mais necessárias devido à inexistência de estendais nos edifícios mais modernos, etc.), mas que implicam cozinhas maiores ou outros espaços complementares (lavandarias, etc.). Mesmo ao nível de outras divisões, o culto do corpo, conjuntamente com um menor tempo de trabalho e um aumento do tempo de lazer, implica a existência de divisões equipadas com alguns apetrechos e/ou para albergar objectos ligados ao lazer, etc. Tais funções não só complexificam os usos do alojamento como são suporte de novos valores habitacionais que o alojamento tem de passar a incorporar.

\section{Modo de vida central e modo de vida suburbano}

Um terceiro eixo de análise aprofundava o confronto entre um modo de vida central e um modo de vida suburbano. Alguns autores afirmam que as condições do habitat, bem como as mobilidades, propiciam diferentes modos de vida aos que vivem no centro das cidades por relação aos que 
vivem nas periferias. Os factores diferenciadores dessas situações urbanas emergem relacionados com a presença de equipamentos (mais escassos na periferia), as mobilidades (grandes consumidoras de tempo) mas também as sociabilidades (ditas mais intensas nas periferias). No entanto, está-se face a conceitos difíceis de lidar teórica e empiricamente já que as periferias da AML recobrem situações suficientemente diversificadas para a as reduzirmos a um conceito único de periferia (da Quinta da Marinha ao Cacém). Daí que este trabalho visasse avaliar, também, a relação entre os motivos de escolha de casa e da sua localização, a satisfação/insatisfação entre viver no centro e periferia, as relações que se estabelecem com família e com os vizinhos, entre outros aspectos.

De facto, cada vez mais o habitat desempenha uma importância crescente na estruturação dos modos de vida, embora de modo diferenciado, de acordo com a classe social, a origem geográfica, a inserção profissional, etc. "De um ponto de vista empírico ressalta a forte componente de investimento das famílias - material, afectivo e simbólico - face ao alojamento, mas também a diversidade das variáveis mediadoras desse investimento" (Guerra, 1998:128). Torna-se, pois, de importância cada vez mais relevante o estudo, de um ponto de vista multidisciplinar, da relação complexa entre habitat e modos de vida possibilitando assim um melhor conhecimento das famílias, das suas necessidades e aspirações face ao habitat e, ao mesmo tempo, uma melhor "clarificação das propostas de intervenção no habitat" (Guerra, 1998:128).

\section{Algumas conclusões do estudo ${ }^{5}$}

\section{A permanência da família no contexto das actuais transformações societais}

As mudanças civilizacionais que atravessaram o mundo nas últimas décadas e que, muito especialmente, foram vividas em Portugal com a revolução do 25 de Abril, não podem deixar de influenciar a instituição familiar, as suas necessidades e funções.
Em todo o lado, e em particular em Portugal (com a ausência de um Estado-Providência que faz revalorizar as funções das famílias), a família continua a representar um dos pilares da sociedade actual e as teses que há uns anos apresentavam o fim inevitável da família parecem postas em causa. Esta conclusão não constitui, de forma alguma, novidade, pois todos os estudos actuais vão neste sentido. Segundo Kaufman, "é verdade que o brusco aumento do número de divórcios, as recusas de casamento, as famílias monoparentais, os nascimentos fora do casamento, as pessoas vivendo sós, dão a impressão de um afrouxamento da instituição (família). Mas são somente as formas que mudam. Elas tornam-se mais soltas e movimentadas (o que não significa mais frágeis) em consequência do papel cada vez maior do sentimento amoroso. Não há, pois, crise mas, de uma certa forma, retorno à normalidade do antagonismo entre estabilidade do casal instalado e a imprevisibilidade perturbadora do amor" (1993: 32).

Cada vez mais nos podemos interrogar se o conceito de família recobre a mesma realidade de outrora ou outra bem diversa. Muitas das funções da família "tradicional" são ainda hoje cumpridas pela família "moderna" mas é verdade que é cada vez mais uma realidade social em profunda mudança É esta dinâmica paradoxal de permanência e variabilidade que parece constituir uma das características mais importantes da instituição familiar. A sua mutação constante é, simultaneamente, a sua força (pela capacidade de adaptação que manifesta) e a sua fragilidade (pela dificuldade da organização social se ajustar a essa mudança permanente). A família moderna parece ser cada vez menos a força do grupo para ser o reforço do sujeito. Individualismo e familismo combinam-se num jogo de interacções sempre em mudança.

Se a família permanece num lugar de destaque, ela sofreu, no entanto, profundas alterações e de forma muito rápida que parecem fazer-se sentir mais ao nível dos valores que das práticas.

Do ponto de vista dos resultados desta pesquisa, embora a maioria dos inquiridos seja casada, a união de facto é aceite. Sendo sobretudo

\footnotetext{
${ }^{5}$ Nos quadros que aqui se incluem os efectivos totais são diferentes entre si e diferentes do total da amostra inquirida. Por um lado, em cada cruzamento existem respostas omissas que, neste questionário, atingiram um valor, por vezes, considerável. Nas questões relacionadas com a partilha das tarefas domésticas só se incluíram os inquiridos vivendo em casal. Por último, quando se analisaram as questões referentes à habitação e habitat, excluíram-se todos os inquiridos que (ainda) não tinham uma habitação autónoma.
} 
nas camadas mais jovens que se verifica a aceitação da união de facto, esta mudança terá tendência a generalizar-se. Analisando o quadro 1, é possível verificar que é nas faixas etárias mais jovens (até aos 40 anos) onde há maior peso de inquiridos a pensarem ser indiferente casar ou viver juntos, enquanto para os mais velhos a importância do casamento assume valores superiores a $50 \%$, o que indicia que a importância do casamento é correlativa à idade.

Quadro 1 - Importância atribuída ao casamento segundo a idade ${ }^{6}$

\begin{tabular}{|c|c|c|c|c|c|c|}
\hline \multirow[t]{2}{*}{$\begin{array}{r}\text { Importância atribuída } \\
\text { ao casamento }\end{array}$} & \multicolumn{2}{|c|}{ Importante casar } & \multicolumn{2}{|c|}{$\begin{array}{l}\text { Indiferente casar ou } \\
\text { viver junto }\end{array}$} & \multicolumn{2}{|c|}{ Total } \\
\hline & freq & $\%$ & freq & $\%$ & freq & $\%$ \\
\hline Até aos 25 anos & 26 & 26,3 & 73 & 73,7 & 99 & 100,0 \\
\hline 26 aos 40 anos & 56 & 37,8 & 92 & 62,2 & 148 & 100,0 \\
\hline 41 aos 64 anos & 64 & 52,9 & 57 & 47,1 & 121 & 100,0 \\
\hline 65 anos e + anos & 22 & 81,5 & 5 & 18,5 & 27 & 100,0 \\
\hline Total & 168 & 42,5 & 227 & 57,5 & 395 & 100,0 \\
\hline
\end{tabular}

Fonte: Inquérito Qualidade de Vida nas Periferias: Habitat e Vida Familiar na Área Metropolitana de Lisboa (1997-2000)

Por outro lado, a aceitação da separação ou divórcio é praticamente unânime. Num país de tradição católica, a esmagadora maioria da amostra considera existirem circunstâncias em que se justifica a dissolução do casamento embora não se possa esquecer que este posicionamento se refere a resultados da AML.

Gráfico 1 - Peso de inquiridos que pensa haver circunstâncias em que é preferível a separação

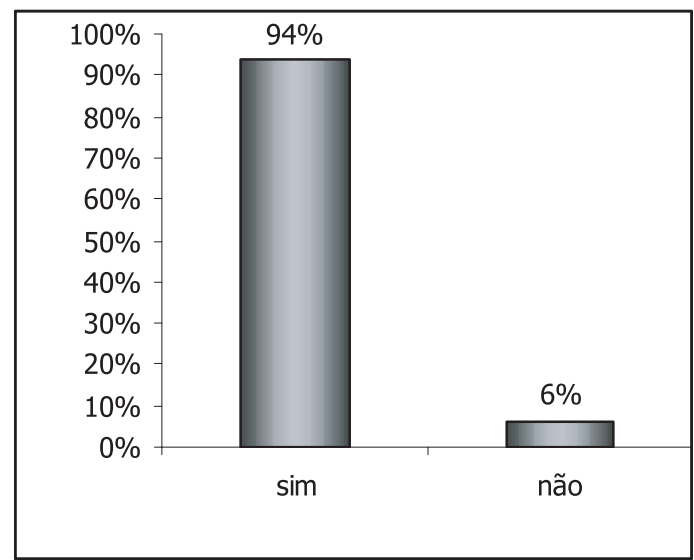

Fonte: Inquérito Qualidade de Vida nas periferias: Habitat e Vida Familiar na Área Metropolitana de Lisboa (1997-2000)

\footnotetext{
${ }^{6}$ Assinala-se a sombreado as células das tabelas de cruzamento onde a frequência relativa é superior à que se esperaria encontrar caso não houvesse relação entre as variáveis. Assim, quando se afirma que uma dada categoria se destaca, não significa que seja essa categoria a apresentar uma maior percentagem, mas sim que tem um peso superior ao esperado na inexistência de relação entre as variáveis. Tal é visível, em termos práticos, quando a categoria apresenta uma percentagem superior à percentagem referente ao total.
} 
As alterações no plano dos valores vão mais longe, ao ponto de se considerar que não existe uma divisão entre tarefas femininas e masculinas.

Quadro 2 - Considera que há tarefas femininas e masculinas?

\begin{tabular}{|l|r|r|}
\hline $\begin{array}{l}\text { Considera que há tarefas masculinas e } \\
\text { femininas? }\end{array}$ & Frequência & $\begin{array}{l}\text { Percentagem } \\
\text { Válida }\end{array}$ \\
\hline Sim & 75 & 18,5 \\
\hline Não & 330 & 81,5 \\
\hline Missing & 19 & ------- \\
\hline Total & 424 & 100 \\
\hline
\end{tabular}

Fonte: Inquérito Qualidade de Vida nas Periferias: Habitat e Vida Familiar na Área Metropolitana de Lisboa (1997-2000)

Contudo, na prática, continuam a ser as mulheres a assegurar a grande maioria das tarefas domésticas e do cuidado com os filhos, embora nas gerações mais jovens e nos casos em que a mulher exerce uma profissão no exterior do lar, se esboce já uma tendência para uma maior democratização nomeadamente nos cuidados com as crianças.

Quadro 3 - Divisão dos papéis domésticos segundo o facto de a mulher desempenhar actividade profissional

\begin{tabular}{|c|r|r|r|r|r|r|}
\hline $\begin{array}{c}\text { Dupla actividade profissional } \\
\text { Papéis domésticos }\end{array}$ & \multicolumn{2}{|c|}{ Sim } & \multicolumn{2}{c|}{ Não } & \multicolumn{2}{c|}{ Total } \\
\hline freq & \multicolumn{2}{|r|}{ freq } & \multicolumn{2}{c|}{ freq } & $\%$ \\
\hline Femininos & 39 & 28,3 & 26 & 61,9 & 65 & 36,1 \\
\hline Mistos com pendor feminino & 68 & 49,3 & 13 & 31,0 & 81 & 45,0 \\
\hline Igualitários & 31 & 22,5 & 3 & 7,1 & 34 & 18,9 \\
\hline Total & 138 & 100,0 & 42 & 100,0 & 180 & 100,0 \\
\hline
\end{tabular}

Fonte: Inquérito Qualidade de Vida nas periferias: Habitat e Vida Familiar na Área Metropolitana de Lisboa (1997-2000)

A valorização da família, por outro lado, continua a ser um facto, em particular da família restrita (cônjuge/companheiro e filhos), embora, num contexto de preservação de um certo individualismo. A integração no grupo familiar, o bem- estar das crianças e o seu acompanhamento são um elemento importante na definição das funções da família e razões que justificam a sua valorização. Relativamente à importância atribuída à família restrita e alargada, tal como pode verificar-se pelo quadro 4, a primeira é objecto de uma valorização superior, o que nos é demonstrado pela diferença entre as médias atribuídas aos dois tipos de famílias.

Quadro 4 - Importância conferida à família restrita e alargada

\begin{tabular}{|l|l|l|l|l|l|}
\hline & $\mathrm{n}$ & Mínimo & Máximo & Média & Desvio-padrão \\
\hline Família restrita & 424 & 4 & 10 & 9.15 & 1.20 \\
\hline Família alargada & 424 & 0 & 10 & 6.85 & 2.15 \\
\hline
\end{tabular}

Fonte: Inquérito Qualidade de Vida nas periferias: Habitat e Vida Familiar na Área Metropolitana de Lisboa (1997-2000)

${ }^{7}$ Por dupla actividade profissional entende-se as situações em que ambos os cônjuges exercem uma actividade profissional. 
Mas se se valoriza a família restrita, a família alargada mantém a sua importância, embora noutro contexto, estabelecendo-se com ela redes importantes de entreajuda. Com o ingresso massivo das mulheres no mercado de trabalho, o papel dos avós no auxílio do cuidado com as crianças, assume um papel de extrema importância para muitas famílias. Refira-se, no entanto, que o peso de outro tipo de ajudas, nomeadamente a dos amigos, representa uma importância não desprezível, indicador potencial de uma diversificação das redes de entreajudas nas sociedades actuais.

Quadro 5 - A quem pediria ajuda não monetária?

\begin{tabular}{|l|c|c|}
\hline $\begin{array}{l}\text { A quem pediria ajuda não } \\
\text { monetária }\end{array}$ & Frequência & Percentagem \\
\hline Pais & 160 & 68,0 \\
\hline Filhos & 38 & 9,5 \\
\hline Irmãos/cunhados & 90 & 36,5 \\
\hline Outros familiares & 51 & 14,9 \\
\hline Amigos & 58 & 16,6 \\
\hline Outros & 63 & 22,4 \\
\hline Total de indivíduos & 241 & 100,0 \\
\hline
\end{tabular}

Fonte: Inquérito Qualidade de Vida nas periferias: Habitat e Vida Familiar na Área Metropolitana de Lisboa (1997-2000)

A importância da família é ainda visível no tipo de valores que os inquiridos consideram importante transmitir aos filhos. A análise desta questão relativamente aos valores a transmitir aos filhos revela que a família continua a deter um lugar de destaque no conjunto dos valores sociais. Nos valores considerados mais importantes, o respeito pela família ocupa o terceiro lugar, logo após a responsabilidade e o respeito pelos outros.

Quadro 6 - Valores mais importantes a transmitir aos filhos

\begin{tabular}{|l|r|r|}
\hline Valores a transmitir aos filhos & freq & \multicolumn{1}{c|}{$\%$} \\
\hline Respeito pela família & 171 & 14,7 \\
\hline Obediência & 28 & 2,4 \\
\hline Autoconfiança & 150 & 12,8 \\
\hline Responsabilidade & 274 & 23,5 \\
\hline Disciplina & 37 & 3,2 \\
\hline Respeito pelos outros & 196 & 16,8 \\
\hline Respeito pelas regras da sociedade & 42 & 3,6 \\
\hline Tolerância & 49 & 4,2 \\
\hline Valor da amizade & 124 & 10,6 \\
\hline Individualismo & 3 & 0,3 \\
\hline Solidariedade & 92 & 7,9 \\
\hline
\end{tabular}

Fonte: Inquérito Qualidade de Vida nas Periferias: Habitat e Vida Familiar na Área Metropolitana de Lisboa (1997-2000) 


\section{A “consonância cognitiva" e o baixo limiar de exigências face ao habitat}

As transformações socio-demográficas da sociedade portuguesa, as alterações nas representações e na estrutura das famílias são acompanhadas de percursos de mobilidade social e habitacional que a pesquisa permite identificar.

Devemos chamar a atenção para o facto de a complexa relação entre família e habitat não ter ficado completamente esclarecida nesta pesquisa. A imensa quantidade de variáveis mediadoras desta relação (a diversidade dos tipos de famílias e das fases do ciclo de vida, a classe social, a localização do trabalho, etc.) e as vicissitudes da pesquisa e do seu financiamento não permitiram uma completa clarificação desta relação.
Porém, os dados recolhidos permitem constatar que, nomeadamente, a importância conferida à proximidade ao centro da cidade estão estreitamente associados ao tipo de família. Como se pode observar pelo Quadro 7, embora a proximidade ao centro não tenha sido uma razão muito indicada como estando na base da escolha da habitação (aliás, para mais de 90\% dos inquiridos, não o foi), são as famílias com crianças que estão dispostas a abdicar do centro da cidade em função de uma necessidade de mais espaço, (o que será apenas possível nas periferias), tal como o tipo sozinho com mais 40 anos e o ninho vazio. Já as famílias casal sem filhos, as famílias monoparentais e os sozinhos com menos de 40 anos apresentam, com um peso superior ao esperado, a proximidade ao centro, como um dos principais motivos de escolha do local de habitação, o que é revelador da maior importância desta variável nos mais jovens e nos novos tipos de família.

Quadro 7 - Escolha da casa em função da proximidade ao centro ${ }^{8}$

\begin{tabular}{|c|c|c|c|c|c|c|}
\hline \multirow[b]{2}{*}{ Tipo de família } & \multicolumn{2}{|c|}{$\begin{array}{l}\text { Proximidade ao } \\
\text { centro não }\end{array}$} & \multicolumn{2}{|c|}{$\begin{array}{l}\text { Proximidade ao } \\
\text { centro sim }\end{array}$} & \multicolumn{2}{|c|}{ Total } \\
\hline & freq & $\%$ & freq & $\%$ & freq & $\%$ \\
\hline Casal sem filhos & 16 & 66,7 & 8 & 33,3 & 24 & 100,0 \\
\hline Casal com filhos crianças & 38 & 82,6 & 8 & 17,4 & 46 & 100,0 \\
\hline Casal com filhos de outras idades & 59 & 80,8 & 14 & 19,2 & 73 & 100,0 \\
\hline Monoparentais & 14 & 73,7 & 5 & 26,3 & 19 & 100,0 \\
\hline Sózinho com menos de 40 anos & 23 & 71,9 & 9 & 28,1 & 32 & 100,0 \\
\hline Ninho vazio & 24 & 82,8 & 5 & 17,2 & 29 & 100,0 \\
\hline Sózinho com mais de 40 anos & 18 & 78,3 & 5 & 21,7 & 23 & 100,0 \\
\hline Outras situações & 17 & 94,4 & 1 & 5,6 & 18 & 100,0 \\
\hline Total & 205 & 89,5 & 54 & 23,6 & 229 & 100,0 \\
\hline
\end{tabular}

Fonte: Inquérito Qualidade de Vida nas Periferias: Habitat e Vida Familiar na Área Metropolitana de Lisboa (1997-2000)

Também o estatuto de ocupação parece relacionar-se com o tipo de família, destacando-se, desde logo, que a grande maioria dos inquiridos reside em regime de propriedade do alojamento.
Contudo, a casa própria está especialmente associada às famílias com filhos, se exceptuarmos as famílias monoparentais.

\footnotetext{
${ }^{8}$ Para a abordagem das questões da família, optou-se por construir uma tipologia de famílias próxima da de Laslett (1974). No entanto, posteriormente, quando se analisaram as variáveis referentes ao habitat, sentiu-se a necessidade de construir uma tipologia de famílias que, por um lado, contemplasse de alguma forma as fases do ciclo de vida e, por outro, excluísse os inquiridos que não viviam numa habitação autónoma, logo por eles não escolhida.
} 
Quadro 8 - Estatuto de ocupação por tipo de família

\begin{tabular}{|c|c|c|c|c|c|c|}
\hline \multirow{2}{*}{$\begin{array}{l}\text { Estatuto de ocupação } \\
\text { Tipo de família }\end{array}$} & \multicolumn{2}{|c|}{ Casa arrendada } & \multicolumn{2}{|c|}{ Casa própria } & \multicolumn{2}{|c|}{ Total } \\
\hline & freq & $\%$ & freq & $\%$ & freq & $\%$ \\
\hline Casal sem filhos & 7 & 33,3 & 14 & 66,7 & 21 & 100,0 \\
\hline Casal com filhos crianças & 7 & 14,9 & 40 & 85,1 & 47 & 100,0 \\
\hline Casal com filhos de outras idades & 12 & 17,4 & 57 & 82,6 & 69 & 100,0 \\
\hline Monoparentais & 7 & 41,2 & 10 & 58,8 & 17 & 100,0 \\
\hline Sózinho com menos de 40 anos & 11 & 39,3 & 17 & 60,7 & 28 & 100,0 \\
\hline Ninho vazio & 5 & 19,2 & 21 & 80,8 & 26 & 100,0 \\
\hline Sózinho com mais de 40 anos & 6 & 33,3 & 12 & 66,7 & 18 & 100,0 \\
\hline Outras situações & 6 & 37,5 & 10 & 62,5 & 16 & 100,0 \\
\hline Total & 61 & 25,2 & 181 & 74,8 & 242 & 100,0 \\
\hline
\end{tabular}

Fonte: Inquérito Qualidade de Vida nas Periferias: Habitat e Vida Familiar na Área Metropolitana de Lisboa (1997-2000)

A mesma relação podemos encontrar quanto à importância atribuída à propriedade do alojamento. Se bem que a propriedade seja considerada muito importante ou importante pela maioria dos inquiridos (73\% - cf. Gráfico 2) são essencialmente as famílias com filhos (crianças ou adultos), quem se destaca na importância conferida ao facto de possuir casa própria (Quadro 9). Esta associação está de acordo com outros estudos segundo os quais a casa, entendida como património e legado a deixar aos filhos, assume particular relevância quando existe descendência. São também os grupos sociais com menores recursos quem mais importância atribui à propriedade. De facto, a propriedade da casa pode, nestes casos, ser representada como um bem socialmente valorizado, um património importante para quem não tem outros recursos, constituindo uma segurança em caso de desemprego prolongado, doença, etc.

Gráfico 2 - Importância atribuída à casa própria

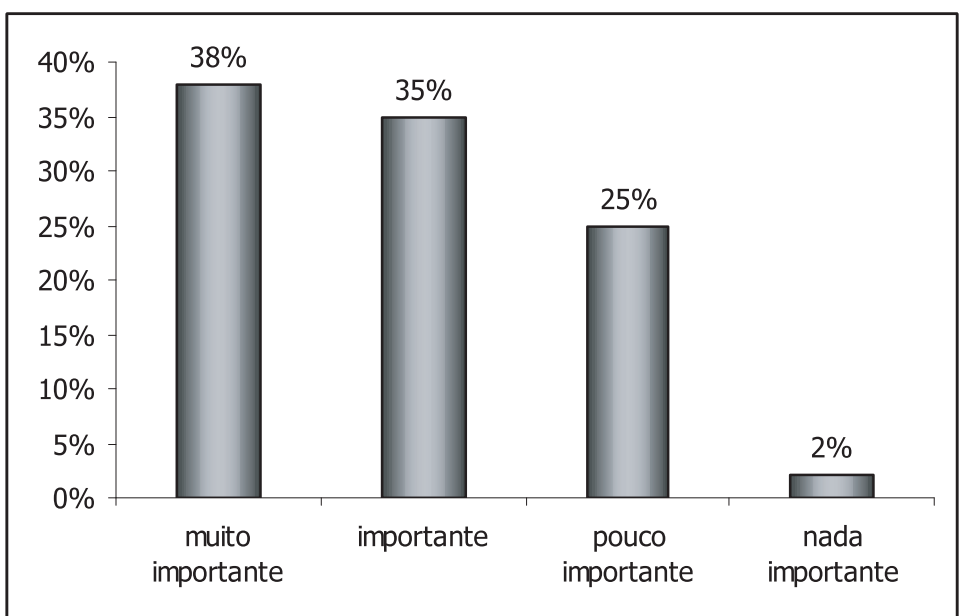

Fonte: Inquérito Qualidade de Vida nas Periferias: Habitat e Vida Familiar na Área Metropolitana de Lisboa (1997-2000) 
Quadro 9 - Importância atribuída à propriedade por tipo de família

\begin{tabular}{|c|c|c|c|c|c|c|c|c|}
\hline \multirow{2}{*}{$\begin{array}{l}\text { Importância atribuída à propriedade } \\
\text { Tipo de família }\end{array}$} & \multicolumn{2}{|c|}{$\begin{array}{c}\text { Muito } \\
\text { importante }\end{array}$} & \multicolumn{2}{|c|}{ Importante } & \multicolumn{2}{|c|}{$\begin{array}{l}\text { Pouco/nada } \\
\text { importante }\end{array}$} & \multicolumn{2}{|c|}{ Total } \\
\hline & freq & $\%$ & freq & $\%$ & freq & $\%$ & freq & $\%$ \\
\hline Casal sem filhos & 4 & 19,0 & 9 & 42,9 & 8 & 38,1 & 21 & 100,0 \\
\hline Casal com filhos crianças & 24 & 51,1 & 12 & 25,5 & 11 & 23,4 & 47 & 100,0 \\
\hline Casal com filhos de outras idades & 32 & 47,8 & 27 & 40,3 & 8 & 11,9 & 67 & 100,0 \\
\hline Monoparentais & 8 & 42,1 & 7 & 36,8 & 4 & 21,1 & 19 & 100,0 \\
\hline Sózinho com menos de 40 anos & 11 & 34,4 & 11 & 34,4 & 10 & 31,3 & 32 & 100,0 \\
\hline Ninho vazio & 12 & 44,4 & 9 & 33,3 & 6 & 22,2 & 27 & 100,0 \\
\hline Sózinho com mais de 40 anos & 6 & 28,6 & 10 & 47,6 & 5 & 23,8 & 21 & 100,0 \\
\hline Outras situações & 4 & 23,5 & 4 & 23,5 & 9 & 52,9 & 17 & 100,0 \\
\hline Total & 101 & 40,2 & 89 & 35,5 & 61 & 24,3 & 251 & 100,0 \\
\hline
\end{tabular}

Fonte: Inquérito Qualidade de Vida nas Periferias: Habitat e Vida Familiar na Área Metropolitana de Lisboa (1997-2000)

No que diz respeito ao grau de satisfação com a casa habitada, a pesquisa permite revelar, em geral, uma apreciação positiva face às condições habitacionais actuais. A análise desta questão revela uma satisfação sem utopia, dando luz a uma tendência de conformidade e a uma valorização do

Gráfico 3 - Satisfação face à casa habitada

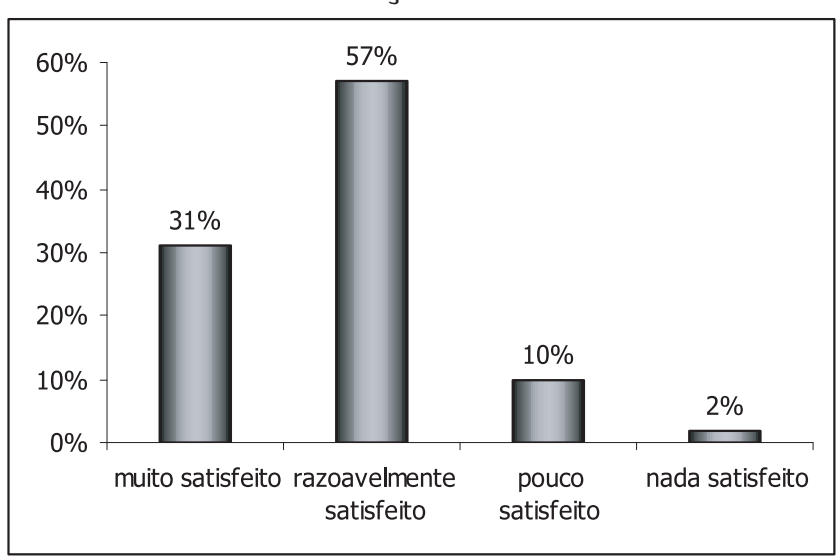

que se tem na apreciação do habitat. Os três factores responsáveis por esta satisfação estão relacionados dominantemente com o interior do alojamento, com a qualidade dos arredores e com as acessibilidades aos bens de primeira necessidade.

Gráfico 4 - Satisfação face aos arredores

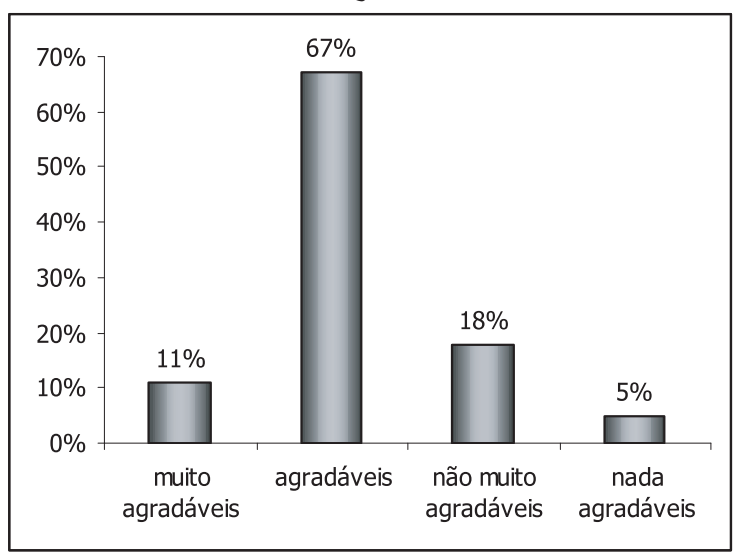

Fonte: Inquérito Qualidade de Vida nas Periferias: Habitat e Vida Familiar na Área Metropolitana de Lisboa (1997-2000)

Colocando a hipótese de um baixo nível de exigência - advindo, em larga medida, de uma apreciação positiva dos percursos de mobilidade, a pesquisa demonstra a satisfação face às actuais condições de vida que a casa permite. Acrescentese que essa satisfação se revela mesmo face a variáveis que habitualmente se critica nas periferias: acessos, equipamentos, qualidade urbanística, etc.

Mas esta satisfação não é acrítica nem apaziguadora de novos sonhos. As sinergias disponíveis para novos percursos de mobilidade estão presentes, pese embora o princípio da realidade parecer sobrepor-se ao princípio do 
desejo. Note-se que mais de metade dos inquiridos pensam (ou gostariam) de mudar de casa e, quando confrontados com a casa ideal, essa casa, regra geral, afasta-se largamente da habitação onde agora residem e que afirmam agradar-lhes.

Admite-se que exista, pois, um conformismo que se pensa não ser alheio ao facto da maioria dos inquiridos habitar em casa própria que se encontra a pagar ou já pagou com esforço e que, por este motivo, se torna objecto de maior valorização e satisfação. Será também este um dos factores que conduz os residentes em habitações arrendadas a mostrar um menor nível de satisfação não só em relação à casa como também em relação às áreas envolventes, às acessibilidades, etc.

Gráfico 5 - Gostaria de mudar de casa?

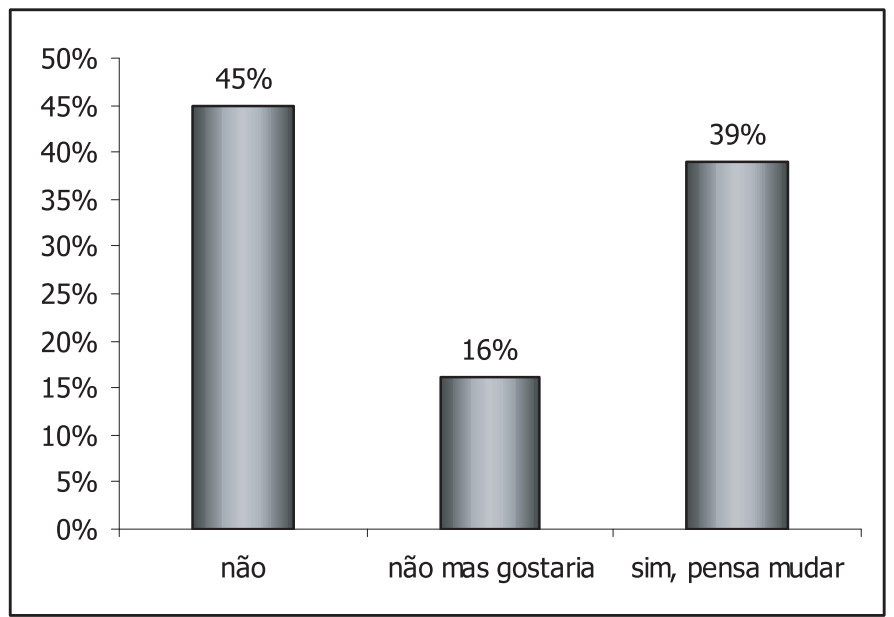

Fonte: Inquérito Qualidade de Vida nas Periferias: Habitat e Vida Familiar na Área Metropolitana de Lisboa (1997-2000)

\section{A "divisão socio-espacial das famílias" que vivem no centro e nas periferias}

Uma das linhas de pesquisa exploradas dizia respeito às características diferenciadoras entre o centro e as periferias quanto a variáveis definidoras do perfil social das respectivas populações habitantes. As populações das periferias, quando comparadas com as de Lisboa, destacam-se pela sua estrutura etária mais jovem face ao envelhecimento do centro. Não é de estranhar, pois, que quanto aos tipos de família se verifique em Lisboa um maior peso das pessoas sós, enquanto nas periferias têm peso superior ao total da amostra dos elementos de famílias de casais com filhos.

Gráfico 6 - Classe etária por área de residência

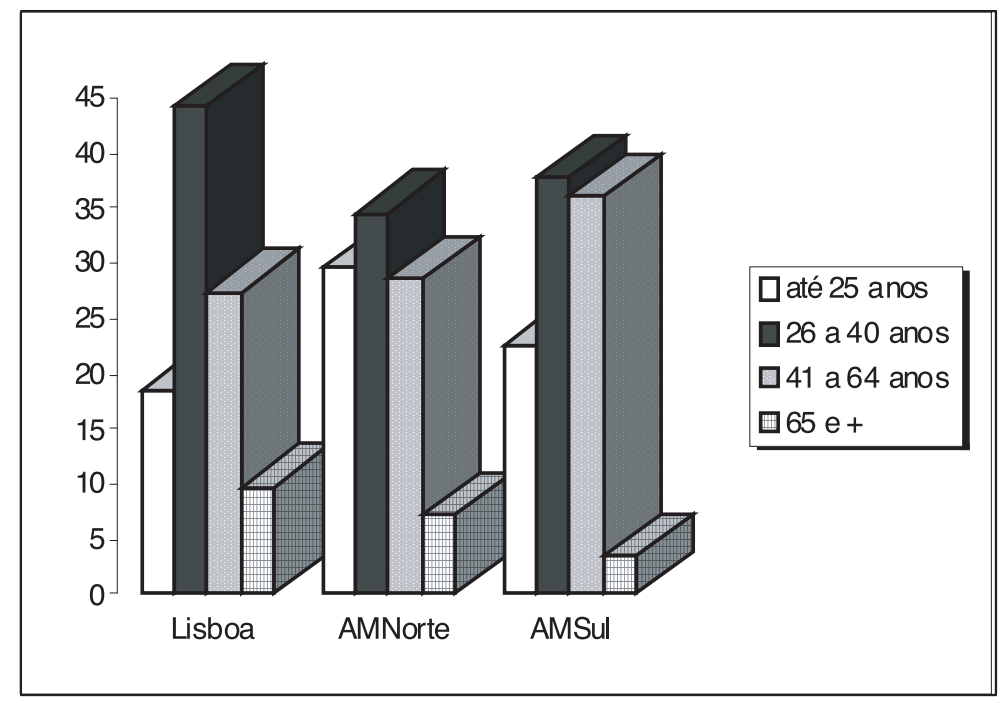

Fonte: Inquérito Qualidade de Vida nas periferias: Habitat e Vida Familiar na Área Metropolitana de Lisboa (1997-2000) 
Do ponto de vista da estrutura de qualificações escolares, os residentes em Lisboa apresentam um nível de escolaridade superior aos das outras duas áreas metropolitanas (embora seja também aqui que assumem um peso superior ao espectável as categoriais referentes às habilitações mais baixas).

Quadro 10 - Nível de escolaridade por área de residência

\begin{tabular}{|c|c|c|c|c|c|c|c|c|}
\hline \multirow[b]{2}{*}{ Nível de escolaridade } & \multicolumn{2}{|c|}{ Lisboa } & \multicolumn{2}{|c|}{ Amnorte } & \multicolumn{2}{|c|}{ Amsul } & \multicolumn{2}{|c|}{ Total } \\
\hline & freq & $\%$ & freq & $\%$ & freq & $\%$ & freq & $\%$ \\
\hline Não sabe ler nem escrever & 2 & 1,8 & 2 & 1,1 & 1 & 0,8 & 5 & 1,2 \\
\hline Sabe ler e escrever & 4 & 3,5 & 3 & 1,6 & 1 & 0,8 & 8 & 1,9 \\
\hline 1. ${ }^{\circ}$ ciclo do ensino básico & 10 & 8,8 & 20 & 11,0 & 15 & 12,6 & 45 & 10,9 \\
\hline 2. ciclo do ensino básico & 4 & 3,5 & 11 & 6,0 & 7 & 5,9 & 22 & 5,3 \\
\hline 3. ciclo do ensino básico & 8 & 7,1 & 22 & 12,1 & 18 & 15,1 & 48 & 11,6 \\
\hline Ensino secundário & 32 & 28,3 & 63 & 34,6 & 51 & 42,9 & 146 & 35,3 \\
\hline Curso médio & 8 & 7,1 & 15 & 8,2 & 5 & 4,2 & 28 & 6,8 \\
\hline Curso superior & 40 & 35,4 & 43 & 23,6 & 20 & 16,8 & 103 & 24,9 \\
\hline Mestrado & 4 & 3,5 & 3 & 1,6 & 1 & 0,8 & 8 & 1,9 \\
\hline Doutoramento & 1 & 0,9 & --- & --- & --- & --- & 1 & 0,2 \\
\hline Total & 113 & 100,0 & 182 & 100,0 & 119 & 100,0 & 414 & 100,0 \\
\hline
\end{tabular}

Fonte: Inquérito Qualidade de Vida nas Periferias: Habitat e Vida Familiar na Área Metropolitana de Lisboa (1997-2000)

Esta diferenciação é também visível na estrutura de classes. Os Empresários, Dirigentes e Profissionais Liberais, bem como os Profissionais Técnicos e de Enquadramento e os Trabalhadores Independentes assumem, em Lisboa, um peso superior ao do total da amostra. Por outro lado, os
Empregados Executantes e os Operários distinguem-se nas duas áreas metropolitanas periféricas (Quadro 11). Poderão ser estas características que, a par com as diferenças das próprias regiões, explicam as diferenças de opinião a seguir explicitadas.

Quadro 11 - Áreas de residência segundo as classes sociais

\begin{tabular}{|c|c|c|c|c|c|c|c|c|}
\hline \multirow[b]{2}{*}{ Classe social } & \multicolumn{2}{|c|}{ Lisboa } & \multicolumn{2}{|c|}{ Amnorte } & \multicolumn{2}{|c|}{ Amsul } & \multicolumn{2}{|c|}{ Total } \\
\hline & freq & $\%$ & freq & $\%$ & freq & $\%$ & freq & $\%$ \\
\hline $\begin{array}{l}\text { Empresários, dirigentes, profissionais } \\
\text { liberais }\end{array}$ & 5 & 5,9 & 3 & 2,3 & --- & --- & 8 & 2,6 \\
\hline Profissionais técnicos de enquadramento & 36 & 42,4 & 41 & 31,3 & 30 & 31,6 & 107 & 34,4 \\
\hline Trabalhadores independentes & 11 & 12,9 & 11 & 8,4 & 11 & 11,6 & 33 & 10,6 \\
\hline Empregados executantes & 29 & 34,1 & 59 & 45,0 & 41 & 43,2 & 129 & 41,5 \\
\hline Operários & 4 & 4,7 & 17 & 13,0 & 13 & 13,7 & 34 & 10,9 \\
\hline Total & 85 & 100,0 & 131 & 100,0 & 95 & 100,0 & 311 & 100,0 \\
\hline
\end{tabular}

Fonte: Inquérito Qualidade de Vida nas periferias: Habitat e Vida Familiar na Área Metropolitana de Lisboa (1997-2000) 
Uma das questões analisadas tendo em conta esta possível diferenciação, diz respeito aos motivos de escolha da casa. Se os principais factores que estiveram na base da escolha da casa foram, geralmente, o seu preço, a proximidade/acessibilidade ao local de trabalho e/ou escola e a dimensão da habitação, no que diz respeito à análise destas variáveis por área de residência, verifica-se que o preço das casas se faz sentir essencialmente nas periferias de Lisboa (áreas metropolitanas a norte e a sul do Tejo).

A proximidade ao trabalho e/ou escola, bem como a dimensão/qualidade da habitação são características referidas em primeiro lugar pelas famílias da cidade de Lisboa embora assumam grande peso também nas periferias, pois aparecem logo a seguir ao preço das casas.

Obviamente, para os residentes em Lisboa a proximidade/acessibilidade ao centro da cidade adquire uma grande importância, o que não acontece com os residentes na periferia. E quando se fala de proximidade ao centro fala-se em proximidade face a equipamentos culturais, de lazer, etc., que ou não existem na periferia ou existem de forma insuficiente (Quadro 12).

Quadro 12 - Motivos de escolha da casa por área de residência

\begin{tabular}{|c|c|c|c|c|c|c|}
\hline Área de residência & Lis & & Am & orte & & \\
\hline Motivo escolha da casa & freq & $\%$ & freq & $\%$ & freq & $\%$ \\
\hline Acessibilidade económica/preço das casas & 31 & 33,3 & 97 & 57,4 & 45 & 45,5 \\
\hline Dimensão/ qualidade da habitação & 39 & 41,9 & 69 & 40,8 & 35 & 35,4 \\
\hline $\begin{array}{l}\text { Proximidade/acessibilidade ao local de } \\
\text { trabalho e/ou escola }\end{array}$ & 47 & 50,5 & 80 & 47,3 & 42 & 42,4 \\
\hline $\begin{array}{l}\text { Proximidade/acessibilidade ao centro da } \\
\text { cidade }\end{array}$ & 33 & 35,5 & 28 & 16.6 & 13 & 13,1 \\
\hline $\begin{array}{l}\text { Proximidade/acessibilidade a comércio e } \\
\text { serviços }\end{array}$ & 19 & 20,4 & 20 & 11.8 & 12 & 12,1 \\
\hline Proximidade/acessibilidade a familiares & 27 & 29,0 & 48 & 28.4 & 30 & 30,3 \\
\hline Proximidade/acessibilidade a amigos & 8 & 8,6 & 21 & 12.4 & 18 & 18,2 \\
\hline Já aqui vivia & 27 & 29,0 & 41 & 24.3 & 28 & 28,3 \\
\hline Outros & 6 & 6,5 & 22 & 13.0 & 16 & 16,2 \\
\hline
\end{tabular}

Fonte: Inquérito Qualidade de Vida nas periferias: Habitat e Vida Familiar na Área Metropolitana de Lisboa (1997-2000)

Em relação às características propostas no questionário face à satisfação pela casa, todas elas são apreciadas positivamente pelos seus moradores. Realizada uma análise em componentes principais obtêm-se claramente duas componentes: uma de natureza mais objectiva - conforto, qualidade de construção, quantidade de espaço e forma como as divisões estão distribuídas e outra de natureza mais "subjectiva" onde se destacam aspectos como a orientação solar a, calma e a privacidade. 
Quadro 13 - Análise em componentes principais sobre a apreciação da casa

\begin{tabular}{|l|c|c|}
\hline Matriz das componentes rodada & \multicolumn{2}{|c|}{ Componentes } \\
\hline & 1 & \multicolumn{1}{c|}{2} \\
\hline Conforto & 0,785 & 0,239 \\
\hline Forma como as divisões estão distribuídas na casa & 0,738 & $-0,001$ \\
\hline Quantidade de espaço de que dispõe & 0,704 & 0,235 \\
\hline Qualidade da construção & 0,618 & 0,340 \\
\hline Calma/tranquilidade & 0,007 & 0,795 \\
\hline Privacidade & 0,195 & 0,787 \\
\hline Orientação solar/luminosidade & 0,214 & 0,537 \\
\hline
\end{tabular}

Fonte: Inquérito Qualidade de Vida nas Periferias: Habitat e Vida Familiar na Área Metropolitana de Lisboa (1997-2000)

\section{A importância da centralidade, nomeadamente do centro da metrópole}

No que concerne ao grau de satisfação face à área de residência, verifica-se que o mais apreciado é a acessibilidade/proximidade ao centro da cidade, a calma e a tranquilidade, a oferta de equipamentos, serviços e infra-estruturas, o bom relacionamento com os vizinhos, as zonas verdes, de lazer e jardins, e o contacto com a natureza, desigualmente valorizados pelos residentes nas diferentes áreas de residência. Contudo, seja qual for a área de residência, os inquiridos valorizam em primeiro lugar a proximidade face a Lisboa.
A oferta de equipamentos serviços e infra-estruturas é colocado em segundo plano pelos Lisboetas, enquanto as famílias residentes nas áreas metropolitanas valorizam mais a calma e a tranquilidade, características que advêm da periferização. No entanto, as famílias residentes na margem sul referem também a oferta de equipamentos serviços e infra-estruturas enquanto as famílias de Lisboa colocam em terceiro lugar a calma e a tranquilidade. Para os lisboetas é relevante ainda a centralidade, tal como para as famílias da margem sul é importante a proximidade do mar. Seja qual for a área de residência, o bom relacionamento com os vizinhos é uma dimensão valorizada. 
Quadro 14 - O que aprecia mais na área de residência por área de residência?

\begin{tabular}{|c|c|c|c|c|c|c|}
\hline \multirow{3}{*}{$\begin{array}{l}\text { O que mais aprecia Área residência } \\
\text { Acessibilidade/proximidade centro de Lisboa }\end{array}$} & \multicolumn{2}{|c|}{ Lisboa } & \multicolumn{2}{|c|}{ Amnorte } & \multicolumn{2}{|c|}{ Amsul } \\
\hline & freq & $\%$ & freq & $\%$ & freq & $\%$ \\
\hline & 61 & 64.2 & 116 & 68.6 & 53 & 53.5 \\
\hline Calma/tranquilidade & 32 & 33.7 & 91 & 53.8 & 49 & 49.5 \\
\hline Oferta equipamentos/serviços & 44 & 46.3 & 46 & 27.2 & 38 & 38.4 \\
\hline Contacto com a natureza & 6 & 6.3 & 24 & 14.2 & 8 & 8.1 \\
\hline Qualidade das casas & 10 & 10.5 & 10 & 5.9 & 4 & 4.0 \\
\hline Qualidade da urbanização & 3 & 3.2 & 7 & 4.1 & 5 & 5.1 \\
\hline Agradabilidade do sítio & 8 & 8.4 & 14 & 8.3 & 12 & 12.1 \\
\hline Enraizamento/conhecimento & & & 3 & 1.8 & 2 & 2.0 \\
\hline Proximidade familiares/amigos & 3 & 3.2 & 17 & 10.1 & 9 & 9.1 \\
\hline Proximidade do trabalho & 6 & 6.3 & 11 & 6.5 & 6 & 6.1 \\
\hline Bom relacionamento c/vizinho & 22 & 23.2 & 34 & 20.1 & 22 & 22.2 \\
\hline Zonas verdes/de lazer/jardins & 17 & 17.9 & 29 & 17.2 & 19 & 19.2 \\
\hline Boas condições ambientais & 5 & 5.3 & 12 & 7.1 & 6 & 6.1 \\
\hline Ambiente/património histórico & 8 & 8.4 & 2 & 1.2 & & \\
\hline Proximidade do mar & 1 & 1.1 & 13 & 7.7 & 12 & 12.1 \\
\hline Espaço & 1 & 1.1 & 6 & 3.6 & 7 & 7.1 \\
\hline Segurança & 3 & 3.2 & 7 & 4.1 & 3 & 3.0 \\
\hline Facilidade de estacionamento & 2 & 2.1 & 6 & 3.6 & 3 & 3.0 \\
\hline Centralidade & 18 & 18.9 & 2 & 1.2 & 3 & 3.0 \\
\hline Outros & 4 & 4.2 & 18 & 10.7 & 6 & 6.1 \\
\hline
\end{tabular}

Fonte: Inquérito Qualidade de Vida nas Periferias: Habitat e Vida Familiar na Área Metropolitana de Lisboa (1997-2000)

Na aferição da importância da centralidade, colocava-se uma questão em que se pedia aos inquiridos para dizerem se preferiam uma casa grande na periferia ou uma casa pequena em Lisboa. Caso pusessem optar, verifica-se que mais de $80 \%$ escolhe a primeira hipótese Não deixa de ser interessante notar que, para os residentes na cidade de Lisboa, exista um peso considerável dos que optam por uma casa pequena em Lisboa, revelador da importância que a centralidade assume para estes habitantes. A percentagem bastante elevada dos que, residindo na periferia, continuariam a preferir a sua situação periférica, usufruindo, assim, de mais espaço, indicia que a periferização não parece desagradar a quem a vive, embora a escolha da casa tenha sido altamente constrangida por factores económicos. 
Gráfico 7 - Preferia uma casa pequena em Lisboa ou grande na periferia?

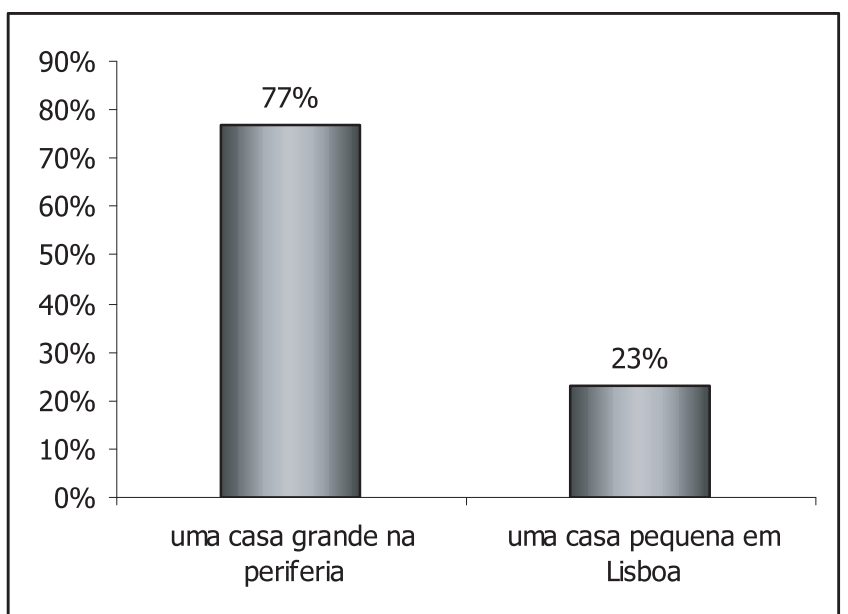

Fonte: Inquérito Qualidade de Vida nas Periferias: Habitat e Vida Familiar na Área Metropolitana de Lisboa (1997-2000)

Quando se analisa o percurso residencial dos inquiridos, a maioria das famílias considera ter mudado para uma casa melhor. Esta situação fica, em grande parte, a dever-se ao facto de terem transitado para uma residência maior, em termos de número médio de assoalhadas.

Gráfico 8 - Mudança de habitação

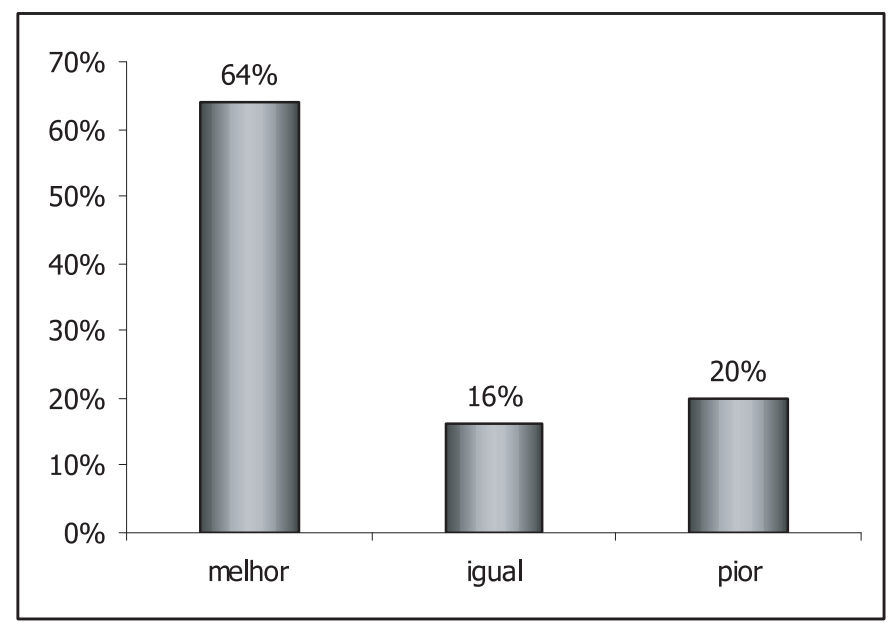

Fonte: Inquérito Qualidade de Vida nas Periferias: Habitat e Vida Familiar na Área Metropolitana de Lisboa (1997-2000)

Porém, quando questionadas sobre a correspondência entre a casa actual e a idealizada, constata-se que são as famílias residentes em Lisboa quem, com maior peso, afirmam que esta casa corresponde totalmente aquela que ansiavam, enquanto a Aréa Metropolitana Norte se distingue por ser aqui que maior percentagem de inquiridos pensam que a sua casa não corresponde em nada à casa idealizada. No cômputo geral, são os residentes na área metropolitana a sul do Tejo que apresentam situações menos extremadas, pois são eles quem se destaca na afirmação de que a sua casa corresponde em parte à que pensavam ter há uns anos. 
Quadro 15 - Correspondência entre a casa actual e a que pensava ter

\begin{tabular}{|l|r|r|r|r|r|r|r|r|}
\hline & \multicolumn{2}{|c|}{ Lisboa } & \multicolumn{2}{c|}{ AMNorte } & \multicolumn{2}{c|}{ AMSul } & \multicolumn{2}{c|}{ Total } \\
\cline { 2 - 9 } & \multicolumn{1}{|c|}{$\mathrm{N}$} & \multicolumn{1}{c|}{$\%$} & $\mathrm{~N}$ & \multicolumn{1}{c|}{$\%$} & $\mathrm{~N}$ & \multicolumn{1}{c|}{$\mathrm{N}$} & $\%$ \\
\hline $\begin{array}{l}\text { Corresponde totalmente ao que } \\
\text { pensava ter }\end{array}$ & 17 & 17,2 & 16 & 9,6 & 12 & 11,0 & 45 & 12,0 \\
\hline Corresponde em parte & 63 & 63,6 & 110 & 66,3 & 78 & 71,6 & 251 & 67,1 \\
\hline Não corresponde em nada & 19 & 19,2 & 40 & 24,1 & 19 & 17,4 & 78 & 20,9 \\
\hline Total & 99 & 100,0 & 166 & 100,0 & 109 & 100,0 & 374 & 100,0 \\
\hline
\end{tabular}

Fonte: Inquérito Qualidade de Vida nas Periferias: Habitat e Vida Familiar na Área Metropolitana de Lisboa (1997-2000)

\section{A urbanização metropolitana sem qualidade: equipamentos, insegurança e estacionamento}

Os principais problemas detectados nas áreas de residência das famílias inquiridas estão principalmente relacionados com as más condições ambientais, o excesso de tráfego, as condições de estacionamento, o défice de equipamentos, serviços e infra-estruturas, a insegurança e transportes públicos. Contudo, estes problemas são sentidos de forma diferenciada nas diversas áreas de residência.

Na cidade de Lisboa não se colocam os problemas das infra-estruturas, como seria de esperar num centro urbano, mas, com maior acuidade, os das más condições ambientais, do excesso de tráfego e das más condições de estacionamento, fruto da vida nas grandes metrópoles. Na área metropolitana do norte é o défice de equipamentos, e só depois o tráfego e o ambiente que são referidos como principais problemas da área de residência. Na área metropolitana do sul, as más condições ambientais são mencionadas como a principal desvantagem desta área. É também aqui que se observa maior concentração industrial, pelo que as más condições ambientais não são decorrentes em exclusivo do excesso de tráfego. As famílias residentes nesta área apontam, de seguida, como factores problemáticos, o excesso de tráfego e o défice de infra-estruturas e equipamentos.

Quadro 16 - Principais problemas da área de residência por área de residência

\begin{tabular}{|c|c|c|c|c|c|c|c|c|}
\hline \multirow{3}{*}{$\begin{array}{l}\text { Principais problemas área residência } \\
\text { Área residência } \\
\text { Lisboa }\end{array}$} & \multicolumn{2}{|c|}{$\begin{array}{c}\text { Défice equipamentos/ } \\
\text { /serviços/infraestruturas }\end{array}$} & \multicolumn{2}{|c|}{ Estacionamento } & \multicolumn{2}{|c|}{$\begin{array}{l}\text { Excesso de } \\
\text { tráfego }\end{array}$} & \multicolumn{2}{|c|}{$\begin{array}{c}\text { Más condições } \\
\text { ambientais }\end{array}$} \\
\hline & freq & $\%$ & freq & $\%$ & freq & $\%$ & freq & $\%$ \\
\hline & 5 & 5,6 & 35 & 38,9 & 43 & 47,8 & 67 & 74,4 \\
\hline Amnorte & 66 & 38,6 & 49 & 28,7 & 62 & 36,3 & 55 & 32,2 \\
\hline Amsul & 23 & 25,3 & 14 & 15,4 & 26 & 28,6 & 50 & 54,9 \\
\hline
\end{tabular}

Fonte: Inquérito Qualidade de Vida nas Periferias: Habitat e Vida Familiar na Área Metropolitana de Lisboa (1997-2000)

\section{Em jeito de conclusão}

Como principais conclusões, salienta-se a importância conferida à família, nomeadamente à família restrita, não obstante as alterações, cada vez mais relevantes, da sua forma, as afirmações no sentido da legitimidade da dissolução do casamento e as crescentes alterações dos papéis assumidos pelos membros do casal. É de referir ainda a importância das ajudas familiares, nomeadamente as levadas a cabo pelos avós às famílias com crianças.

Ao nível do habitat, é de referir a articulação entre a diversidade dos tipos familiares e respectivos modos de vida e a escolha de determinados "habitats" que os permitem concretizar. 
A dimensão da habitação, a par com o seu preço, é um aspecto grandemente valorizado, o que leva um grande número de famílias a optar por casas na periferia. Contudo, algumas situações que podemos incluir nos "novos tipos" de família tendem a valorizar a centralidade e, assim, parecem dispostas a sacrificar as características da dimensão às da localização. Assim, a proximidade ao trabalho e/ou escola, e a proximidade aos equipamentos $d a$ cidade, são características referidas dominantemente pelas famílias habitantes na cidade de Lisboa (embora assumam também um peso não desprezível também nas periferias). A fase do ciclo de vida parece também ser ainda uma variável importante na escolha da área de residência. São as famílias jovens, ainda sem filhos, protagonizando modos de vida reveladores de valores habitacionais de apreço pela centralidade, que valorizam a proximidade face aos equipamentos, nomeadamente de lazer, sacrificando a dimensão da casa, ou mesmo a sua propriedade à sua localização. Também as famílias monoparentais parecem fazê-lo com maior frequência que os outros tipos de família, talvez por outras razões, provavelmente por uma necessidade de aproximação à ajuda nos cuidados das crianças (sejam essas ajudas os avós ou as escolas) e não tanto pela valorização da centralidade enquanto tal. 


\section{Bibliografia}

ABOIM, Sofia; WALL, Karin, 2002, “Tipos de família em Portugal: interacções, valores, contextos", Análise Social, n. ${ }^{\circ}$ 163, Lisboa, ICS, pp. 475-507.

ALMEIDA, Ana Nunes, GUERREIRO, Maria das Dores, 1993, "A famíla" in França, Luís (coord.), Portugal, valores europeus identidade cultural, Lisboa, IED, pp. 181-219.

ALMEIDA, Ana Nunes, GUERREIRO, Maria das Dores; LOBO, Cristina; TORRES, Anália; WALL, Karin, 1989, "Relações familiares: mudança e modernidade", in VIEGAS, José Manuel; COSTA, António, Firmino (org), Portugal que modernidade? Lisboa, Celta, pp. 45-78.

BERTRAND, Jean-René, CHEVALIER, Jacques, 1998 (direc.), Logement et Habitat dans les Villes Europpéennes, Paris, Editions L'Harmattan.

BONVALET, Catherine, 1989, "Évolution des structures familiales et conséquences sur l'habitat en France", in Familles, modes de vie et habitat, Paris, L'Harmattan, pp. 31-53.

BONVALET, Catherine, 1993, Le logement une affaire de famille: l'approche intergénérationnelle des status résidentiels, Paris, Ed. Catherine Bonvalet e Anne Gotman, Ed. L'Harmattan.

BONVALET, Catherine, 1991, "Le logement" in SINGLY, François. (Org.), La famille: l'état des savoirs, Paris, Éditions La Découverte, pp. 165-172.

BONVALET, Catherine, MERLIN, Pierre, 1988, Transformations de la famille et habitat, Cahier n. ${ }^{\circ} 120$, Travaux et Documents, Paris, PUF, pp. 223-233.

BONVALET, Catherine, 1985, L'évolution des structures familiales et ses repercussions sur l'habitat, Paris, Conseil National de l'habitat.

BONVALET, Catherine, BRUN, Jacques; SEGAUD, Marion., 1998, "Introdution", in Logement et habitat: l'état des savoirs, Paris, Éditions La Découverte \& Syros, pp. 5-8.

BOURDIEU, Pierre, SAINT MARTIN, Monique, 1990, "Le sens de la propriété: la genèse sociale des systèmes de préférences, l'économie de la maison", Actes de la Recherche en Sciences Sociales, n. ${ }^{\circ}$ 81/82, Paris, Éditions du Seuil, pp. 52-64.

DE SINGLY, François (org.), 1992a), La famille: l'état des savoirs, Paris, Éditions La Découverte.

DE SINGLY, François, 1992b), Sociologie de la famille contemporaine, Paris, Claire Hennaut, Paris, Éditions La Découverte.

FRANÇA, Luís (coord.), 1993, Portugal, valores europeus identidade cultural, Lisboa, IED.

GIDDENS, Anthony, 2001, O mundo na era da globalização, (3. ${ }^{\text {a }}$ edição), Lisboa, Presença.

GIDDENS, Anthony, 1996, Transformações da intimidade Sexualidade, amor e erotismo nas sociedades modernas, Lisboa, Celta Editora.
GIDDENS, Anthony, 1995, As consequências da modernidade (2. ${ }^{\mathrm{a}}$ edição), Oeiras, Celta Editora.

GIDDENS, Anthony, 1994, Modernidade e identidade pessoal ( $2^{\mathrm{a}}$ edição), Oeiras, Celta Editora.

GUERRA, Isabel, 2002, Famille et habitat au Portugal au debut des années 2000, Reseau socio-economie de l'habitat (policopiado).

GUERRA, Isabel, 2000, "Transformações dos modos de vida e necessidades habitacionais" in A Futura Habitação Apoiada, Lisboa, LNEC/relatório 75/00 - NA, pp. 179-194.

GUERRA, Isabel, 1998, "Grupos sociais, formas de habitat e estrutura dos modos de vida", Sociedade e Território, n. ${ }^{\circ}$ 25/26, Porto, Afrontamento, pp. 118-129.

GUERRA, Isabel, MATIAS, Nelson, 1988, "Elementos para uma análise sociológica do movimento clandestino (1)" in Povos e Culturas - A cidade em Portugal, Centro de Estudos dos Povos e Culturas e Expressão Portuguesa, Universidade Católica Portuguesa, vol. 3, pp. 335-355.

GUERREIRO, Maria das Dores, 1998, “Conciliação entre trabalho e vida familiar e solidariedade intergeracional" in Trabalho, Família e Gerações, Lisboa, CIES pp. 33-38.

HAUMONT, Nicole, SEGAUD, Marion (org.), 1987, Familles, modes de vie et habitat, Actes du Colloque International d'Arc et Senans, Paris, L'Harmattan.

KAUFMANN, Jean, Claude, 1997, Le Cour à l'Ouvrage, Théorie de l'Action Ménagère, Paris, Nathan.

KAUFMANN, Jean-Claude, 1993, Sociologie du couple, col. Que sais-je?, Paris, PUF.

KELLERHALS, Jean, MONTANDON, Cléopâtre, 1992, "Les styles éducatifs" in DE SINGLY, François (org.), $\mathrm{La}$ famille: l'état des savoirs, Paris, Éditions La Découverte, pp. 194-200.

LASLETT, Peter, 1974, "Introduction: the history of the family" in LASLETT, Peter (Edit), Household and Family in Past Time, Londres, Cambridege University Press, pp. 1-85.

LOBO, Cristina, 1995 "Do recasamento às estratégias de recomposição familiar", Sociologia Problemas e Práticas, n. ${ }^{\circ}$ 18, Lisboa, Celta Editora, pp. 69-95.

LUHMANN, Niklas, 1991, O amor como paixão: para a codificação da intimidade, Lisboa, Dífel.

REIS, António (coord.), 1994, Portugal 20 anos de democracia, Lisboa, Círculo de Leitores.

REIS, Elisabeth, 1993, Análise de Clusters: um método de classificação sem preconceitos, Lisboa, ISCTE, GIESTA.

ROUGEMONT, Denis, 1989, O amor e o Ocidente, Lisboa, Assírio Bacelar Editor.

ROUSSEL, Louis, 1989, La famille incertaine, Paris, Éditions Odile Jacob. 
SEGALEN, Martine, 1981, Sociologie de la famille, Paris, Armand Colin.

SEGAUD, Marion (direct.), 1998, Logement et habitat: l'état des savoirs, Paris, Éditions La Découverte \& Syros.

TORRES, Anália, 1987, "Amores e Desamores", Sociologia, Problemas e Práticas, n. ${ }^{\circ}$ 3, Lisboa, CIES, Publicações Europa-América, pp. 21-33.
TORRES, Anália, 2000, Trajectórias, dinâmicas e formas de conjugalidade: assimetrias sociais e de género no casamento, Lisboa, ISCTE (Policopiado).

TORRES, Anália, 2001, Sociologia do casamento, Oeiras, Celta Editora.

VASCONCELOS, Pedro, 2001, Redes de Entreajuda Familiar no Portugal Contemporâneo, Tese de Mestrado, sob a orientação da Professora Doutora Karin Wall, Lisboa, ICS. 